Revista Verde de Agroecologia e Desenvolvimento Sustentável

http://www.gvaa.com.br/revista/index.php/RVADS

ARTIGO CIENTÍFICO

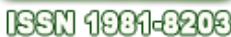

DOI: http://dx.doi.org/10.18378/rvads.v10i5.3640

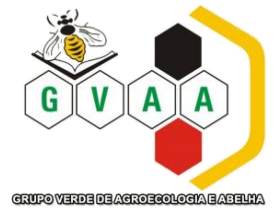

\title{
Avaliação de genótipos de feijão-caupi para produção de grãos verdes em Gurupi, Tocantins
}

\author{
Evaluation of cowpea genotypes for green grain production in Gurupi, state Tocantins

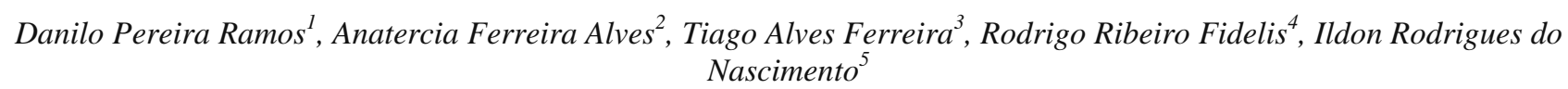

Resumo: O feijão-caupi, também conhecido como feijão-de-corda, é um dos componentes mais importantes da dieta alimentar de povos das regiões tropicais e subtropicais do mundo, sendo a principal fonte de proteína para os agricultores familiares das regiões norte e nordeste do Brasil. Com objetivo de avaliar o potencial de genótipos de feijão-caupi para produção de grãos verdes nas condições de Gurupi-TO, foi conduzido um experimento na estação experimental da Universidade Federal do Tocantins, Campus Universitário de Gurupi, no período de março a maio de 2013. Os tratamentos constituíram-se de vinte genótipos de feijão-caupi, sendo dezesseis linhagens e quatro cultivares. Utilizou-se o delineamento experimental em blocos ao acaso com quatro repetições. A parcela experimental foi representada por quatro linhas de cinco metros de comprimento, com espaçamento de 0,5 m entre linhas, sendo as duas linhas centrais a área útil. Foram avaliados comprimento de vagem, peso de vagem, peso de grãos por vagem, número de grãos por vagem, peso de cem grãos, índice de grãos e produtividade de grãos verdes. As linhagens MNC02-684F-5-6, MNC02-682F-2-6, MNC03-736F-7 e MNC02-683F-1 e as cultivares BRS-ITAIM e BRS-CAUAMÉ destacam-se com indicativo de grande adaptabilidade na região de Gurupi sob regime irrigado.

Palavras-chave: feijão-verde, produtividade, Vigna unguiculata L

\begin{abstract}
The cowpea, also known as feijão-de-corda, is one of the most important components of the diet of peoples in the tropical and subtropical regions of the world, being the main source of protein for the family farmers of the North and Northeast regions of Brazil. With the objective of evaluating the potential of cowpea genotypes for production of green grains under the Gurupi-To conditions, an experiment was conducted in the experimental station of the Universidade Federal do Tocantins [Federal University of Tocantins) Gurupi Campus, in the period of March to May of 2013. The treatments consisted of twenty cowpea genotypes, being sixteen lines and four cultivars. The experimental design in randomized blocks with four replications was utilized. The experimental plot was represented by four rows five meters long, with spacing of $0.5 \mathrm{~m}$ interrows, the two central rows being the useful area. Pod length, pod weight, grain weight per pod, number of grains per pod, weight of one hundred grains, grain index and green grain yield were evaluated. Lines MNC02-684F-5-6, MNC02-682F-2-6, MNC03-736F-7 and MNC02-683F-1 and cultivars BRS-ITAIM and BRS-CAUAMÉ stand out with an indicative of great adaptability in the region of Gurupi under irrigated regime.
\end{abstract}

Key words: green bean, productivity, Vigna unguiculata L

\footnotetext{
*Autor para correspondência

Recebido para publicação em 13/09/2015; aprovado em 15/12/2015

${ }^{1}$ Mestrando na Universidade Federal do Tocantins, Campus Gurupi. E-mail: daniloramos05@hotmail.com;

${ }^{2}$ Professora Adjunta I na Universidade Estadual do Maranhão, CESI-Imperatriz, E-mail: anaterciaa@yahoo.com.br;

${ }^{3}$ Doutorando na Universidade Federal do Tocantins, Campus Gurupi. E-mail: tiagoferreira.agro@ gmail.com;

${ }^{4}$ Professores Adjunto na Universidade Federal do Tocantins, Campus Gurupi. E-mail:fidelisrr@uft.edu.br, ildon@mail.uft.edu.br;
} 


\section{INTRODUÇÃO}

O feijão-caupi [Vigna unguiculata (L.) Walp.], também conhecido como feijão-de-corda, é uma cultura originária da África e um dos componentes mais importantes da dieta alimentar de povos das regiões tropicais e subtropicais do mundo, sendo a principal fonte de proteína para os agricultores familiares das regiões norte e nordeste do Brasil. Nessas regiões, essa cultura destaca-se por sua importância socioeconômica, especialmente para as famílias do meio rural, sendo fundamental para fixação de mão-de-obra no campo, e geração de emprego e renda (FREIRE FILHO et al., 2011).

Possui uma grande variabilidade genética, sendo utilizado para várias finalidades em diversos sistemas de produção, podendo ser comercializado na forma de grãos secos, grãos verdes, vagens verdes e sementes, porém o mercado de feijão-caupi gira em torno, principalmente da produção de grãos secos ou imaturos (ROCHA et al., 2007; ALMEIDA et al., 2010).

De grande importância na região Nordeste e em muitas capitais das regiões Norte, Sudeste e Centro-Oeste do Brasil, o mercado de feijão verde é o segundo maior mercado de feijão-caupi do Brasil (ROCHA et al., 2009), sendo colhido e comercializado na fase que os grãos apresentam entre 50 a $70 \%$ de umidade na forma de vagens ou grãos verdes debulhados (OLIVEIRA et al., 2001; OLIVEIRA et al., 2003 ). Representando um mercado altamente promissor para o feijão-caupi, a produção e consumo de feijão-verde torna-se uma boa opção de renda para os agricultores familiares (FREIRE FILHO et al., 2007).

Mesmo sendo a segunda região produtora e consumidora de feijão-caupi no Brasil, a região Norte ainda apresenta baixa produtividade de grãos, devido a vários fatores como baixo uso de tecnologia pelo pequeno produtor, uso de cultivares pouco adaptadas as condições de cultivo, manejo inadequado da cultura, e a incidência de doenças e pragas, que, juntos diminuem a produtividade das lavouras (MOUSINHO et al., 2008).

A produção de feijão-verde é realizada intensamente por agricultores familiares que não possuem alta tecnologia no cultivo, representando uma fonte alternativa de renda, sendo tratada como uma hortaliça para as famílias da zona rural (ROCHA et al., 2012).

Tendo em vista que a cultura do feijão-caupi é tipicamente de subsistência, não existe grande procura destes produtores por cultivares melhoradas, e quando existe é para produção de grãos secos. Em função dos fatores que interferem na produção do feijão-caupi, os estudos baseados nos rendimento de grãos secos podem não ser o melhor critério para selecionar cultivares superiores. Nesse sentido, alguns estudos têm sido conduzidos, avaliando especialmente a produtividade de grãos e vagens verdes (ANDRADE et al., 2010; ROCHA et al., 2012).

No entanto, ainda há necessidade de estudos e seleção de cultivares de feijão-caupi para produção de grãos verdes, uma vez que a opção por cultivares melhoradas, que tenham características de grãos e vagens compatíveis com a exigência do mercado é de grande importância para se obter sucesso no cultivo.

Assim, objetivou-se avaliar o potencial agronômico de genótipos de feijão-caupi para produção de grãos verdes na cidade de Gurupi- Tocantins.

\section{MATERIAL E MÉTODOS}

O experimento foi conduzido na estação experimental da Universidade Federal do Tocantins (UFT), Campus Universitário de Gurupi, localizado a $11^{\circ} 43^{`} 45^{\prime \prime}$ de latitude sul, $49^{\circ} 04^{\prime} 07^{\prime}$ de longitude oeste e altitude de $278 \mathrm{~m}$, no período de março a maio de 2013. O solo é classificado, como Latossolo Vermelho-Amarelo distrófico (EMBRAPA, 2006). A caracterização climática local é $A w$ Cerrado ou Savana tropical, do tipo mesotérmico com chuvas de verão e inverno seco segundo Koppen- Geiger (PEEL et al., 2007).

O preparo do solo foi realizado de forma convencional, com uma aração e duas gradagens dez dias antes da semeadura. Foram utilizadas sementes selecionadas e devidamente tratadas com defensivos recomendados para a cultura. Os tratos culturais e fitossanitários (adubação, controle de pragas, doenças, e plantas invasoras) foram realizados conforme recomendação para a cultura (FREIRE FILHO et al., 2005).

A irrigação foi realizada de acordo com as necessidades da cultura. Utilizou-se sistema por aspersão convencional com turno de rega de dois dias, tendo um período de funcionamento de duas horas. A vazão dos aspersores utilizados com pressão na base de 20 mca propiciou lâmina d'água de 5,2 mm.h ${ }^{-1}$.

O delineamento experimental utilizado foi em blocos ao acaso com quatro repetições. A parcela experimental foi representada por quatro linhas de $5 \mathrm{~m}$ de comprimento, com espaçamento de $0,5 \mathrm{~m}$ entre linhas. Como área útil foi utilizada as duas linhas centrais, desprezando-se $0,50 \mathrm{~m} \mathrm{em}$ ambas as extremidades.

A semeadura foi realizada em março de 2013, após 10 dias foi realizado o desbaste deixando oito plantas por metro linear, totalizando assim uma população de 160 mil plantas por hectare.

Os tratamentos constituíram-se de vinte genótipos de feijão-caupi oriundos de sementes disponibilizadas pela Embrapa Meio-Norte, sendo dezesseis linhagens e quatro cultivares, totalizando vinte tratamentos: MNC02-675F-4-9, MNC02-675F-4-10, MNC02-675F-9-2, MNC02-675F-9-3, MNC02-676F-3, MNC02-682F-2-6, MNC02-683F-1, MNC02-684F-5-6, MNC03-725F-3, MNC03-736F-7, MNC03-737F-5-1, MNC03-737F-5-4, MNC03-737F-5-9, MNC03-737F-5-10, MNC03-737F-5-11, MNC03-737F-11, BRS-TUCUMAQUE, BRS-CAUAMÉ, BRS-ITAIM, BRSGUARIBA.

Para verificar o desempenho dos genótipos de feijãocaupi, foram avaliados comprimento de vagem (CV), peso de vagem $(\mathrm{PV})$, peso de grãos por vagem $(\mathrm{PGV})$, número de grãos por vagem (NGV), peso de cem grãos (P100G), índice de grãos verdes (IG) e produtividade de grãos verdes (PRO.G).

Os dados experimentais foram submetidos à análise de variância e aplicação do teste F. Para as comparações entre as médias dos tratamentos, foi utilizado o teste de Tukey a 5\% de probabilidade. Utilizou-se, para análises, o aplicativo computacional GENES (CRUZ, 2013).

\section{RESULTADOS E DISCUSSÃO}

Os resumos das análises de variância de comprimento de vagem, peso de vagem, peso de grãos por vagem, número de grãos por vagem, peso de cem grãos, índice de grãos e 
produtividade de grãos verdes são apresentados na tabela 1 . Para as fontes de variação Genótipos e Linhagens verifica-se que houve efeito significativo para todos os caracteres avaliados, com exceção de número de grãos por vargem e peso de cem grãos, indicando que os genótipos e linhagens diferem entre si. Para Cultivares verificou-se significância em comprimento de vagem, peso de vagem, índice de grãos e produtividade de grãos verdes.

Para a interação Linhagens vs. Cultivares verificou-se significância apenas para produtividade de grãos verdes, indicando que há variabilidade genética entre linhagens e cultivares, com possibilidade de seleção entre os genótipos.

Tabela 1. Resumo da análise de variância de comprimento de vagem (CV), peso de vagem (PV), peso de grãos por vagem (PGV), número de grãos por vagem (NGV), peso de cem grãos (P100G), índice de grãos (IG) e produtividade de grãos verdes (PRO.GV) de vinte genótipos de feijão-caupi. Gurupi, Tocantins

\begin{tabular}{lcccccccc}
\hline \multirow{2}{*}{ Fontes de variação } & \multicolumn{9}{c}{ Quadrados Médios } \\
\cline { 2 - 9 } & GL & CV & PV & PGV & NGV & P100G & IG & PRO.G \\
\hline Repetição & 3 & 6,88 & 4,96 & 0,51 & 7,89 & 49,11 & 30,85 & 9105,31 \\
Genótipos & 19 & $4,50^{* *}$ & $8,51^{* *}$ & $0,72^{* *}$ & $4,32^{\text {ns }}$ & $31,12^{\text {ns }}$ & $173,07^{* *}$ & $578310,97^{* *}$ \\
Linhagens & 15 & $4,07^{* *}$ & $9,03^{* *}$ & $0,85^{* *}$ & $4,86^{\text {ns }}$ & $33,59^{\text {ns }}$ & $192,04^{* *}$ & $488552,45^{* *}$ \\
Cultivares & 3 & $8,01^{* *}$ & $8,63^{* *}$ & $0,23^{\text {ns }}$ & $1,13^{\text {ns }}$ & $18,26^{\text {ns }}$ & $111,19^{* *}$ & $458645,44^{* *}$ \\
Linhag vs. Cultivares & 1 & $0,30^{\text {ns }}$ & $0,38^{\text {ns }}$ & $0,19^{\text {ns }}$ & $5,83^{\text {ns }}$ & $32,70^{\text {ns }}$ & $74,14^{\text {ns }}$ & $2283685,32^{* *}$ \\
Resíduo & 57 & 1,73 & 1,91 & 0,27 & 3,46 & 21,89 & 20,84 & 34575,97 \\
\hline Média Geral & & 18,53 & 9,62 & 3,45 & 11,91 & 28,12 & 36,42 & 1483,22 \\
Médias Linhagens & & 18,50 & 9,59 & 3,43 & 12,05 & 27,80 & 36,91 & 1398,74 \\
Médias Cultivares & & 18,66 & 9,76 & 3,55 & 11,37 & 29,39 & 34,50 & 1821,13 \\
CV $(\%)$ & & 7,10 & 14,36 & 15,17 & 15,62 & 16,64 & 12,53 & 12,54 \\
\hline
\end{tabular}

NS ${ }^{* *} \mathrm{e}^{*}$ Não significativo e significativo a $1 \%$ e $5 \%$ de probabilidade, respectivamente, pelo teste F.

Na tabela 2 é apresentado as médias de comprimento de vagem, peso de vagem, peso de grãos por vagem, número de grãos por vagem, peso de cem grãos, índice de grãos e produtividade de grãos verdes. Em relação ao comprimento de vargens verdes, podemos observar que houve diferença significativa entre os tratamentos com médias variando de $15,70 \mathrm{~cm}$ (MNC03-737F-5-10) a 19,99 cm (BRSTUCUMAQUE).

Tabela 2. Médias de comprimento de vagem (CV), peso de vagem (PV), peso de grãos por vagem (PGV), número de grãos por vagem $(\mathrm{NGV})$, peso de cem grãos (P100G), índice de grãos (IG) e produtividade de grãos verdes (PRO.GV) de vinte genótipos de feijão-caupi. Gurupi, Tocantins

\begin{tabular}{|c|c|c|c|c|c|c|c|}
\hline Genótipos & $\begin{array}{l}\mathrm{CV} \\
(\mathrm{cm})\end{array}$ & $\begin{array}{l}\text { PV } \\
(\mathrm{g})\end{array}$ & $\begin{array}{l}\text { PGV } \\
(\mathrm{g})\end{array}$ & $\begin{array}{l}\text { NGV } \\
\text { (und) }\end{array}$ & $\begin{array}{c}\text { P100G } \\
(\mathrm{g})\end{array}$ & $\begin{array}{l}\mathrm{IG} \\
(\%)\end{array}$ & $\begin{array}{l}\text { PRO.GV } \\
\left(\mathrm{kg} \mathrm{ha}^{-1}\right)\end{array}$ \\
\hline MNC02-675F-4-9 & $19,36 \mathrm{a}$ & $10,96 \mathrm{ab}$ & $3,83 \mathrm{ab}$ & $13,30 \mathrm{a}$ & $29,12 \mathrm{a}$ & 40,04abcde & 1653 cdef \\
\hline MNC02-675F-4-10 & $19,69 \mathrm{a}$ & $11,46 \mathrm{ab}$ & $3,79 \mathrm{ab}$ & $14,15 \mathrm{a}$ & $28,10 \mathrm{a}$ & 39,40abcde & 1379 defgh \\
\hline MNC02-675F-9-2 & $17,82 \mathrm{ab}$ & $9,28 \mathrm{abc}$ & $2,90 \mathrm{ab}$ & $11,15 \mathrm{a}$ & $23,95 \mathrm{a}$ & $28,42 \mathrm{de}$ & $1096 \mathrm{gh}$ \\
\hline MNC02-675F-9-3 & $18,98 \mathrm{ab}$ & $11,22 \mathrm{ab}$ & $2,79 a b$ & $11,80 \mathrm{a}$ & $24,10 \mathrm{a}$ & $28,08 \mathrm{e}$ & $942 \mathrm{~h}$ \\
\hline MNC02-676F-3 & $19,37 \mathrm{a}$ & $10,54 \mathrm{ab}$ & $4,06 a b$ & $11,85 \mathrm{a}$ & $26,76 \mathrm{a}$ & $29,57 \mathrm{de}$ & $1210 \mathrm{fgh}$ \\
\hline MNC02-682F-2-6 & $18,43 \mathrm{ab}$ & $9,76 \mathrm{abc}$ & $3,45 a b$ & $11,20 \mathrm{a}$ & $30,95 \mathrm{a}$ & 35,32 bcde & $1773 \mathrm{abcd}$ \\
\hline MNC02-683F-1 & $18,22 \mathrm{ab}$ & $9,70 \mathrm{abc}$ & $3,45 a b$ & $13,15 \mathrm{a}$ & $26,38 \mathrm{a}$ & 35,93 bcde & 1712 bcde \\
\hline MNC02-684F-5-6 & $18,14 \mathrm{ab}$ & $8,22 \mathrm{abc}$ & $3,28 \mathrm{ab}$ & $11,55 \mathrm{a}$ & $28,53 \mathrm{a}$ & $40,27 \mathrm{abcd}$ & $2182 \mathrm{ab}$ \\
\hline MNC03-725F-3 & $18,86 \mathrm{ab}$ & $9,29 \mathrm{abc}$ & $4,10 \mathrm{a}$ & $12,55 \mathrm{a}$ & $32,80 \mathrm{a}$ & $51,17 \mathrm{a}$ & $1105 \mathrm{gh}$ \\
\hline MNC03-736F-7 & $19,94 \mathrm{a}$ & $11,71 \mathrm{a}$ & $3,90 \mathrm{ab}$ & $13,50 \mathrm{a}$ & $28,66 \mathrm{a}$ & $29,36 \mathrm{de}$ & $1737 \mathrm{bcde}$ \\
\hline MNC03-737F-5-1 & $18,14 \mathrm{ab}$ & $8,11 \mathrm{abc}$ & $3,13 \mathrm{ab}$ & $12,30 \mathrm{a}$ & $24,60 \mathrm{a}$ & $42,77 \mathrm{abc}$ & $1059 \mathrm{gh}$ \\
\hline MNC03-737F-5-4 & $18,32 \mathrm{ab}$ & $8,14 \mathrm{abc}$ & $3,79 a b$ & $11,90 \mathrm{a}$ & $31,70 \mathrm{a}$ & $46,47 \mathrm{ab}$ & 1430 defgh \\
\hline MNC03-737F-5-9 & $17,64 \mathrm{ab}$ & 8,04 bc & $2,94 \mathrm{ab}$ & $10,15 \mathrm{a}$ & $26,97 \mathrm{a}$ & 39,32abcde & 1280efgh \\
\hline MNC03-737F-5-10 & $15,70 \mathrm{~b}$ & $6,34 \mathrm{c}$ & $2,70 \mathrm{~b}$ & $10,30 \mathrm{a}$ & $23,46 \mathrm{a}$ & $42,11 \mathrm{abc}$ & $1188 \mathrm{fgh}$ \\
\hline MNC03-737F-5-11 & $18,27 \mathrm{ab}$ & $10,32 \mathrm{ab}$ & $3,68 \mathrm{ab}$ & $12,15 \mathrm{a}$ & $26,15 \mathrm{a}$ & 30,86 cde & $1007 \mathrm{gh}$ \\
\hline MNC03-737F-11 & 19,18 a & $10,31 \mathrm{ab}$ & $3,12 \mathrm{ab}$ & $11,80 \mathrm{a}$ & $31,50 \mathrm{a}$ & 31,44 cde & 1619 cdef \\
\hline BRS-TUCUMAQUE & 19,99 a & $11,36 \mathrm{ab}$ & $3,88 \mathrm{ab}$ & $12,05 \mathrm{a}$ & $31,53 \mathrm{a}$ & 32,61 cde & $1629 \mathrm{cdef}$ \\
\hline BRS-CAUAMÉ & $16,70 \mathrm{ab}$ & $7,87 \mathrm{bc}$ & $3,60 \mathrm{ab}$ & $10,90 \mathrm{a}$ & $30,93 \mathrm{a}$ & $42,35 \mathrm{abc}$ & 2226 a \\
\hline BRS-ITAIM & $18,66 \mathrm{ab}$ & $9,52 \mathrm{abc}$ & $3,35 \mathrm{ab}$ & $11,00 \mathrm{a}$ & $29,60 \mathrm{a}$ & 32,04 cde & $1958 \mathrm{abc}$ \\
\hline BRS-GUARIBA & $19,28, \mathrm{a}$ & $10,30 \mathrm{ab}$ & $3,40 \mathrm{ab}$ & $11,55 \mathrm{a}$ & $27,51 \mathrm{a}$ & $31,01 \mathrm{cde}$ & 1469 defg \\
\hline
\end{tabular}

Médias seguidas de mesma letra na coluna não diferem entre si estatisticamente pelo teste de Tukey a 5\% de probabilidade. 
Observa-se que o teste de Tukey $(\mathrm{P} \leq 0,05)$ estabeleceu três grupos de genótipos (A, $\mathrm{AB}$ e $\mathrm{B})$. O grupo $\mathrm{A}$ inclui genótipos com maior comprimento de vagem, compreendendo cinco linhagens (MNC02-675F-4-9, MNC02675F-4-10, MNC02-676F-3, MNC03-736F-7, MNC03-737F11), que apresentam comportamentos semelhantes às cultivares BRS-TUCUMAQUE e BRS-GUARIBA e foram superiores às demais cultivares; o grupo $A B$ inclui genótipos com comprimento de vagem intermediário, compreendendo dez linhagens e as cultivares BRS-CAUAMÉ e BRS-ITAIM; já o grupo $\mathrm{B}$ inclui genótipos com menor comprimento de vagem, compreendendo apenas a linhagem /MNC03-737F-510 .

Os resultados obtidos neste trabalho para esta característica corroboram os descritos por Silva et al. (2013) que observaram médias para o comprimento de vargens variando entre 15,5 a $20,91 \mathrm{~cm}$. Considerando que a preferência do mercado de feijão verde é por vagens grandes e atrativas (acima de $18,00 \mathrm{~cm}$ ) (FREIRE FILHO et al., 2005), as linhagens do grupo A podem ser muito promissoras para indicação de cultivo na região ou em programas de melhoramento que almejam selecionar esta característica.Para peso de vagem, podemos observar maior média para a linhagem MNC03-736F-7 (11,71 gramas), diferindo apenas das linhagens MNC03-737F-5-9 (8,04 gramas) e MNC03737F-5-10 (6,34 gramas) e da cultivar BRS-CAUAMÉ $(7,87$ gramas) (Tabela 2). Estes resultados são próximos aos descritos por Borges et al. (2013), onde avaliando cultivares de feijão-caupi para produção de grãos verdes no município de Mossoró, em Rio Grande do Norte, encontraram médias de peso de vagem variando de 7,71 a 10,16 gramas.

Quanto ao peso de grãos por vagem, as médias variaram de 2,70 (MNC03-737F-5-10) a 4,10 gramas (MNC03-725F3). Foi estabelecido três grupos de genótipos (A, AB e B), sendo o grupo A formado apenas pela linhagem $\mathrm{MNC03}$ 725F-3 (maior média); o grupo AB, com médias inferiores ao grupo A, é formado pelos demais genótipos, com exceção da linhagem MNC03-737F-5-10 com menor média, que compõe o grupo B (Tabela 2).

Não houve diferença significativa entre as cultivares que também não diferiram significativamente das demais linhagens, com exceção das linhagens MNC03-725F-3 (maior média) e MNC03-737F-5-10 (menor média) (Tabela 2). Contestando os resultados do presente trabalho, Borges et al. (2013), não observaram significância para esta característica, obtendo médias variando entre 3,42 a 4,44 gramas.

Não foi observado diferenças significativas para as características número de grãos por vagem e peso de cem grãos (Tabela 2). Estes resultados corroboram com os descritos por Borges et al. (2013), que também não observaram significância para estas características em Mossoró-RN. Nessa mesma linha de pesquisa, Rocha et al. (2007) e Andrade (2010) observaram significância para estas características e obtiveram médias variando entre 12 a 15 grãos por vagem verde e 25 a 45 gramas o peso de cem grãos verdes.

Para a característica índice de grãos (Tabela 2), podemos observar maior média para a linhagem MNC03-725F-3 (51,17 $\%$ ), diferindo significativamente de onze genótipos, incluindo a linhagem MNC02-675F-9-3 com menor média (28,08\%). Os resultados obtidos neste trabalho são similares aos encontrados por Silva et al. (2013) onde observaram médias para índice de grãos variando de 28, 52 a 58,79 \% .

Oliveira et al. (2009) avaliando o desempenho de genótipos de feijão-caupi em Aquidauana-MS, obtiveram valores médios superiores para esta característica variando de 53,17 a 75,89\%. Conforme Freire-Filho et al. (2005), o índice de grãos é um parâmetro importante para selecionar cultivares produtoras, pois, o mesmo mede a eficiência no que se refere à alocação de fotoassimilados para os grãos.

Com relação à produtividade de grãos (Tabela 2), observa-se que as linhagens MNC02-682F-2-6 e MNC02684F-5-6 não diferiram das cultivares que se destacaram, BRS-ITAIM e BRS-CAUAMÉ, e foram superiores as demais.

As linhagens apresentaram produtividade com média geral de $1398,74 \mathrm{~kg} \mathrm{ha}^{-1}$, no entanto a linhagem MNC02684F-5-6 destacou-se com valor de $2182 \mathrm{~kg} \mathrm{ha}^{-1}$, superior às cultivares BRS-TUCUMAQUE, BRS-GUARIBA e BRSITAIM. Dentre as linhagens estudadas individualmente, houve também outras superiores às cultivares BRSTUCUMAQUE e BRS-GUARIBA.

Estes resultados são superiores aos encontrado por Silva et al. (2013), que avaliando potencial de cultivares de feijãocaupi para a produção de grãos verdes nas condições de Serra Talhada em Pernambuco encontraram média inferiores.

\section{CONCLUSÕES}

As linhagens MNC02-684F-5-6, MNC02-682F-2-6, MNC03-736F-7 e MNC02-683F-1 apresentam potencial para produção de grãos verdes na região de Gurupi-TO, sob regime irrigado.

As cultivares BRS-ITAIM e BRS-CAUAMÉ destacamse com indicativo de grande adaptabilidade na região de Gurupi sob regime irrigado.

\section{REFERÊNCIAS}

ALMEIDA， A.L.G. de; ALCÂNTARA， R.M.C.M. de; NÓBREGA, R.S.A.; NÓBREGA, J.C.A.; LEITE, L.C. ; SILVA, J.A.L. de. Produtividade do feijão-caupi cv BR 17 Gurguéia inoculado com bactérias diazotróficas simbióticas no Piauí. Revista Brasileira de Ciências Agrárias, v.5, n.3, p.364-369, 2010.

ANDRADE, F. N. Avaliação e seleção de linhagens de tegumento e cotilédone verdes para o mercado de feijão-caupi verde. Teresina: UFPI, 2010.

ANDRADE, F. N.; ROCHA, M. DE M.; GOMES, R. L. F.; FREIRE FILHO, F. R.; RAMOS, S. R. R. Estimativa de parâmetros em genótipos de feijão-caupi avaliados para feijão fresco. Revista Ciência Agronômica, v. 41, n. 2, p. 253-258, 2010 .

BORGES, T. J. Q. DA C.; SILVA, T. A. G.; OLIVEIRA, G. B. S.; SILVA NETO, J. S. DE S.; SILVEIRA, L. M. DE; ANTÔNIO, R. P.; TORRES FILHO, J.; BARROS JÚNIOR, A. P. Avaliação de cultivares de feijão-caupi para produção de grãos verdes no município de Mossoró-RN. In: CONGRESSO NACIONAL DE FEIJAO-CAUPI, 3, 2013, 
Recife. Anais do Congresso Nacional de Feijao-caupi, 2013. CD-ROM.

CRUZ, C. D. GENES - a software package for analysis in experimental statistics and quantitative genetics. Acta Scientiarum, v. 35, n. 3, p. 271-276, 2013.

EMBRAPA. Centro Nacional de Pesquisa de Solos. Sistema Brasileiro de Classificação de Solos. 2.ed. Rio de Janeiro: Embrapa solos, 2006.

FREIRE FILHO, F. R.; LIMA, J. A. A.; RIBEIRO, V. Q. Feijão-caupi: avanços tecnológicos. Teresina: Embrapa Informação Tecnológica, 2005.

FREIRE FILHO, F. R.; RIBEIRO, V. Q.; ROCHA, M. DE M.; SILVA, K. J. D.; NOGUEIRA, M. DO S. DA R.; RODRIGUES, E. V. Feijão-Caupi no Brasil: produção, melhoramento genético, avanços e desafios. Teresina: Embrapa Meio Norte, 2011.

FREIRE FILHO, F. R.; ROCHA, M. DE M.; RIBEIRO, V. Q.; RAMOS, S. R. R.; MACHADO, C. DE F. Novo gene produzindo cotilédone verde em feijão-caupi. Revista Ciência Agronômica, v. 38, n. 03, p. 286-290, 2007.

MOUSINHO, F. E. P.; ANDRADE JÚNIOR, A. S.; FRIZZONE, J. A. Viabilidade econômica do cultivo irrigado do feijão-caupi no Estado do Piauí. Acta Scientiarun Agronomy, v.30, p.139-145, 2008.

OLIVEIRA, A. P.; ARAÚJO, J. S.; ALVES, E. U.; NORONHA, M. A. S.; CASSIMIRO, C. M.; MENDONÇA, F. G. Rendimento de feijão-caupi cultivado com esterco bovino e adubo mineral. Horticultura Brasileira, v. 19, n. 1, p. 81-84, 2001.

OLIVEIRA, A. P.; SILVA, V. R. F.; ARRUDA, F. P.; NASCIMENTO, I. S.; ALVES, A. U. Rendimento de feijãocaupi em função de doses e formas de aplicação de nitrogênio. Horticultura Brasileira, v. 21, n. 1, p. 77-80, 2003.

OLIVEIRA, L. V. A.; CORREA, A. M. Desempenho de genótipos de feijão-caupi em Aquidauana/MS. In: ENCONTRO NACIONAL DE INICIAÇÃO CIENTÍFICA, 1, Aquidauana, 2009. Livro de Resumos. v. 7. 2009. p. 0104.

PEEL, M. C.; FINLA YSON, B. L.;. MCMAHON, T. A. Update world map of the Koppen-Geiger climate classification. Hydrology and Earth System Sciences, v. 11, n 5, p. 1633-1644, 2007.

ROCHA, M. DE M.; ANDRADE, F. N.; GOMES, R. L. F.; FREIRE FILHO, F. R.; RAMOS, S. R. R.; RIBEIRO, V. Q. Adaptabilidade e estabilidade de genótipos de feijão-caupi quanto à produção de grãos frescos, em Teresina-PI. Revista Científica Rural, v. 14, n. 1, p. 40-55, 2012.

ROCHA, M. DE M.; CARVALHO, Q. J. M.; FREIRE FILHO, F. R.; LOPES, A. C. DE A.; GOMES, R. L. F.; SOUSA, I. DA S. Controle genético do comprimento do pedúnculo em feijão-caupi. Pesquisa Agropecuária Brasileira, v. 44 , n. 3 , p. $270-275,2009$.

ROCHA, M. DE M.; SOARES, M. C.; FREIRE FILHO, F. R.; RAMOS, S. R. R.; RIBEIRO, V. Q. Avaliação preliminar de genótipos de feijão-caupi para feijão verde. Revista científica Rural, v. 12, n. 1. p. 153-156, 2007.

SILVA, E. F.; JÚNIOR, A. P. B.; SILVEIRA, L. M.; SANTANA, F. M. DE S.; SANTOS, M. G. Avaliação de cultivares de feijão-caupi irrigado para produção de grãos verdes em Serra Talhada-PE. Revista Caatinga, v. 26, n. 1, p. 21-26, 2013. 